\title{
Quantitative high-resolution observations of soil water dynamics in a complicated architecture using time-lapse ground-penetrating radar
}

\author{
P. Klenk, S. Jaumann, and K. Roth \\ Institute of Environmental Physics, Heidelberg University, Im Neuenheimer Feld 229, 69120 Heidelberg, Germany \\ Correspondence to: P. Klenk (patrick.klenk@iup.uni-heidelberg.de)
}

Received: 10 October 2014 - Published in Hydrol. Earth Syst. Sci. Discuss.: 4 November 2014

Revised: - - Accepted: 5 February 2015 - Published: 2 March 2015

\begin{abstract}
High-resolution time-lapse ground-penetrating radar (GPR) observations of advancing and retreating water tables can yield a wealth of information about near-surface water content dynamics. In this study, we present and analyze a series of imbibition, drainage and infiltration experiments that have been carried out at our artificial ASSESS test site and observed with surface-based GPR. The test site features a complicated but known subsurface architecture constructed with three different kinds of sand. It allows the study of soil water dynamics with GPR under a wide range of different conditions. Here, we assess in particular (i) the feasibility of monitoring the dynamic shape of the capillary fringe reflection and (ii) the relative precision of monitoring soil water dynamics averaged over the whole vertical extent by evaluating the bottom reflection. The phenomenology of the GPR response of a dynamically changing capillary fringe is developed from a soil physical point of view. We then explain experimentally observed phenomena based on numerical simulations of both the water content dynamics and the expected GPR response.
\end{abstract}

\section{Introduction}

A quantitative description of near-surface soil water dynamics is of paramount interest across a range of disciplines in the Earth sciences, from hydrologic research to irrigation management, encompassing a multitude of applications on various scales, from locally predicting contaminant flow and plot-scale precision agriculture all the way to the application of basin-scale hydrologic models (Vereecken et al., 2008).
However, due to considerable spatial heterogeneity and temporal variability of soil water content, quantitative monitoring of soil water dynamics has remained a challenge, especially at intermediate scales, despite considerable efforts and advances in recent years (Robinson et al., 2008). To bridge that gap, electromagnetic geophysical measurement methods have been investigated throughout the last two decades to observe soil water dynamics up to the field scale. For example, high-frequency electromagnetic methods such as timedomain reflectometry (TDR) and ground-penetrating radar (GPR) have received considerable attention, due to their high sensitivity to variations in the dielectric permittivity of the subsurface. Such variations are foremost connected to differences in soil water content due to the large permittivity difference between water and air.

One standard method for achieving high time resolution monitoring of point-scale soil water dynamics is to install a series of TDR probes in selected soil profiles (Robinson et al., 2003). TDR methods are widely recognized for their high accuracy; however, employing TDR probes is a costly and invasive technique, which cannot be transferred easily from one field site to the next. More recently, wireless soil moisture networks have been established at selected field sites, expanding the scope of such 1-D point-scale measurements for directly addressing field-scale soil water content variability (e.g., Bogena et al., 2010).

In contrast, GPR is an electromagnetic geophysical method, which may be employed in both non-invasive surface-based and invasive borehole measurement schemes (e.g., Slob et al. (2010) for an overview). Under equilibrium conditions, significant water content variations in the subsurface are usually associated with differing material proper- 
ties. This leads for example to permittivity variations across soil layer boundaries that typically give rise to partially reflected GPR signals (e.g., Annan, 2005). These layer boundary reflections can in turn be mapped by surface-based GPR systems with high spatial resolution over potentially large distances. The features of the resulting radargram data can then be interpreted, for example in terms of subsurface architecture such as sediment structure (e.g., Neal, 2004; Jol and Bristow, 2003). If multi-channel data are available, both soil water content and reflector depths can be simultaneously calculated from common offset data sets, for example based on a ray path assumption (e.g., Gerhards et al., 2008; Wollschläger et al., 2010; Westermann et al., 2010), or with a constructive inversion approach (Buchner et al., 2012). However, under transient conditions, single-instant in time measurements of seemingly clear reflections can prove difficult to interpret, as shall be briefly touched upon in this paper.

A range of surface-based GPR measurement methods have been repeatedly demonstrated to be applicable for highresolution monitoring of near-surface soil water variations (e.g., Huisman et al., 2003a, b; Grote et al., 2003; Galagedara et al., 2003; Truss et al., 2007; Steelman and Endres, 2010). However, quantification of results derived from surfacebased methods has often remained challenging (e.g., Weihermüller et al., 2007; Huisman and Bouten, 2003; Klenk et al., 2011) or restricted to specific field conditions, such as the presence of ice-layer or precipitation-induced wave guides (e.g., van der Kruk et al., 2006; Strobbia and Cassiani, 2007; van der Kruk et al., 2010; Busch et al., 2012). More recently, successful field-scale monitoring of soil water content variations by off-ground GPR has been reported, assuming planary-layered media (e.g., Minet et al., 2011, 2012, both studies are based on Lambot et al., 2004, 2006). Currently, such full-waveform-based inversion schemes of offground data sets are being adapted to account for near-field effects (Lambot and André, 2014), while Busch et al. (2014) reported on a full waveform inversion scheme of multi-offset ground wave data sets for both dielectric permittivity and electric conductivity, which includes an explicit optimization of the source wavelet. Demonstrating the attainable relative precision of monitoring soil water dynamics based on an onground common offset GPR measurement setup without a similarly involved evaluation scheme will be another aspect of this paper.

Provided highly accurate GPR observations are available over a preferably large range of soil water contents, monitoring soil water dynamics with GPR in connection with a suitable inversion scheme can in principle give access to soil hydraulic properties. So far, several studies have shown promise in inferring near-surface soil hydraulic properties based on time-lapse observations of soil water dynamics, using borehole GPR (e.g., Kowalsky et al., 2005; Rucker and Ferré, 2004; Looms et al., 2008), off-ground GPR (e.g., Jadoon et al., 2008; Lambot et al., 2009; Tran et al., 2014), and multi-offset on-ground GPR (Busch et al., 2013). Follow- ing a different approach, Moysey (2010) estimated soil hydraulic properties based on hydrologic trajectories derived from fixed-offset time-lapse monitoring of an infiltration experiment by on-ground GPR.

Another method for deriving soil hydraulic properties with GPR is to study the shape of the GPR reflection generated by the transition zone above a water table. In the past, this reflection has often been entirely attributed to a successful detection of the groundwater table (e.g., Roth et al., 2004; Doolittle et al., 2006). Other studies have already noted that the dynamics of the transition zone above the capillary fringe as observed during pumping tests might even dominate the GPR response (e.g., Bevan et al., 2003). In that study, neglecting transition zone effects on the GPR signal led to a significant underestimation of the total water volume extracted from an aquifer from GPR data. In a smaller setup, Bano (2006) investigated the transition zone in a sand tank with GPR, reporting a strong dependency of the observed signal on the specific hydraulic situation. A brief review of these and a few further GPR-based studies concerned with detecting water tables until 2006 has been provided by Slater and Comas (2009).

In terms of GPR, the transition zone above a groundwater table in a homogeneous medium is just a smooth variation in dielectric permittivity. The corresponding conversion can be described by a suitable petrophysical relationship. This permittivity variation gives rise to a corresponding GPR reflection resulting from the coherent superposition of a series of infinitesimal contributions along this permittivity profile. The shape of this transition zone is essentially determined by the specific soil hydraulic properties, and hence is in turn the shape of the resulting GPR reflection. Therefore, studying the transition zone reflection with GPR can give access to soil hydraulic properties of sandy soils that feature a shallow groundwater table, such as river plains and sea and lake shores, as well as permafrost and periglacial environments. Following this line, Dagenbach et al. (2013) have reported on time-lapse observations of the transition zone reflection during an imbibition and drainage experiment. In that study, due to the limited range of the induced hydraulic dynamics, no significant variations of the static transition zone signal were observed. Nevertheless, the shape of the measured GPR response already allowed deciding on an appropriate parameterization for the corresponding soil water characteristic function through a joint approach of hydraulic and electromagnetic modeling. More recently, Bradford et al. (2014) have explored the estimation of hydraulic properties from monitoring an aquifer water table during a pumping test with GPR, noting the requirement for observing sufficiently large dynamical changes.

This study continues the path towards estimating hydraulic parameters from high-resolution monitoring of soil water dynamics and in particular time-lapse measurements of the dynamic shape of the transition zone signal by on-ground GPR. Our main objective here is to analyze and interpret from an 
experimental point of view the dynamic evolution of the transition zone above a water table as measured through multitemporal GPR measurements over a large range of dynamic conditions. In particular, we will assess the experimental capabilities of our GPR setup with respect to detailed observations of deliberately induced transition zone dynamics and show that we can consistently reproduce the observed transient phenomena with numerical simulations.

\section{Materials and methods}

We discuss two experiments -1 and 2 - that were carried out at the ASSESS test site close to Heidelberg.

\subsection{The ASSESS site}

In order to facilitate the understanding of hydraulic soil processes and further state-of-the-art GPR measurement and modeling methods, an artificial test bed was built in June 2010 into a former drive-in fodder silo close to Heidelberg. Using three distinct kinds of sand, a complicated but well-defined quasi-2-D architecture was designed and implemented as a $20 \mathrm{~m}$ long, $4 \mathrm{~m}$ wide and approximately $1.9 \mathrm{~m}$ deep test bed for ground-penetrating radar (Buchner et al., 2012). Figure 1a shows the resulting subsurface architecture. As can be seen in this sketch, there are regions of different complexity with respect to the soil water dynamics and the expected GPR signal evaluation, including two- and three-layer regions, slanted reflectors and a synclinal structure. Figure $1 \mathrm{~b}$ shows an exemplary radargram, measured at a center frequency of $400 \mathrm{MHz}$ along the middle of the ASSESS site. Comparing this radargram with the sketch of the subsurface structure demonstrates that major structural elements can be well resolved all the way to the bottom reflection of the test bed, which is visible at approximately $45 \mathrm{~ns}$. In addition to the subsurface layer reflections, a distinct reflected signal can be discerned at an arrival time of about $27 \mathrm{~ns}$, which is governed by the hydrologic state of the system. The temporal variations of this signal will be the main focus of this paper. The ASSESS site is equipped with a series of TDR probes measuring water content dynamics along several 1-D soil profiles. The GPR simulations presented in this work rely on hydraulic parameters derived from a 2-D inversion of TDR data recorded during a previous imbibition and drainage experiment.

\subsection{Experimental overview}

The position of the water table can be adjusted by pumping water into and out of a well located at approximately $18 \mathrm{~m}$ at the far end of the site. These imposed forcings will be denoted as imbibition and drainage, respectively. Furthermore, we can impose an approximately constant infiltration flux from above with a series of sprinklers mounted in a wooden
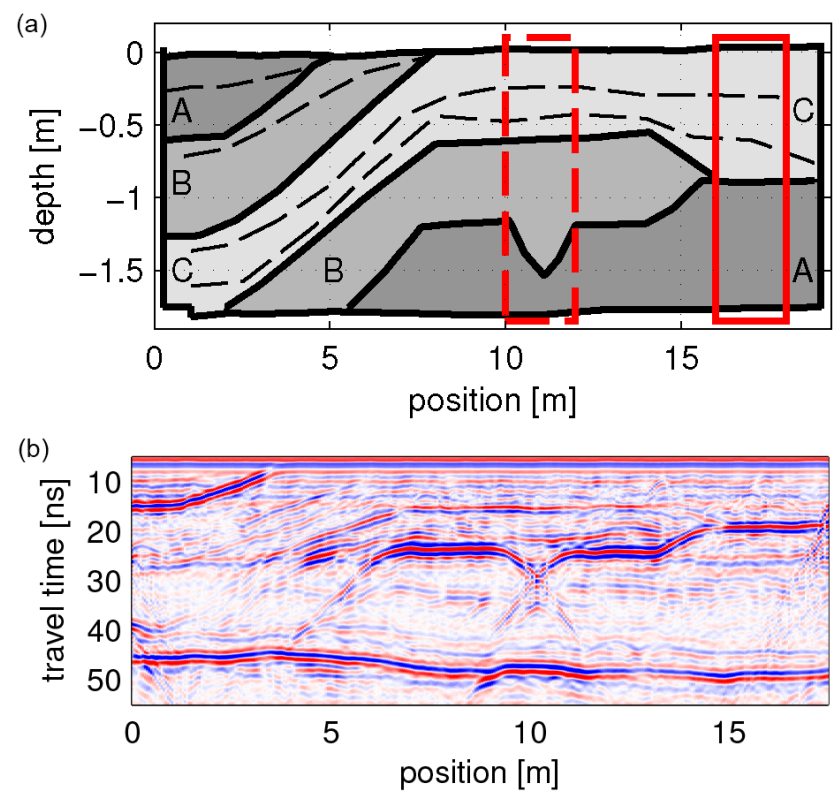

Figure 1. (a) Overview of the subsurface architecture of the ASSESS test site. Solid black lines indicate the layer boundaries between the three different kinds of sand (A, B and C). Dashed black lines indicate known compaction layers, which are an artifact of the building process. The solid (dashed) red rectangle denotes the region for the water content measurements illustrated in Fig. 8a and b. (b) Exemplary radargram acquired by an IDS $400 \mathrm{MHz}$ antenna. A linearly increasing gain function has been applied for increasing the visibility of lower layer features.

frame, distributing water close to the sand surface over an area of approximately $1.0 \times 0.2 \mathrm{~m}$.

During experiment 1, a series of imbibition, equilibration and drainage periods was monitored with GPR. At first, $10.0810 \pm 0.0001 \mathrm{~m}^{3}$ of water was pumped into the well at an approximately constant rate over the course of about $5.3 \mathrm{~h}$, which translates to an imbibition rate of $2.38 \mathrm{~cm} \mathrm{~h}^{-1}$. After $1 \mathrm{~h}$ of equilibration time, $9.5630 \pm 0.0001 \mathrm{~m}^{3}$ of water was pumped out again, at a drainage rate of $3.42 \mathrm{~cm} \mathrm{~h}^{-1}$. Over the whole course of experiment 1 , four-channel GPR data have been acquired along a stretch of the site at a temporal resolution of approximately one radargram per minute.

The aim of experiment 2 was to investigate the hydraulic dynamics during a period of infiltration followed by a period of imbibition. GPR observations were obtained at the same temporal resolution as during the previous experiment. Ten days prior to experiment 2, a greenhouse roof had been built above the ASSESS site, ensuring the absence of significant precipitation-induced infiltration fronts in the top soil. The experiment started with infiltrating $0.2113 \pm 0.0001 \mathrm{~m}^{3}$ of water from above into the two-layered part of the structure with the infiltration device centered at $17 \mathrm{~m}$ over the course of $1.6 \mathrm{~h}$. This leads to a highly localized infiltration pulse. The detailed spreading of this infiltration pulse in the subsurface is a 3-D effect. In our case, we expect a well-defined 


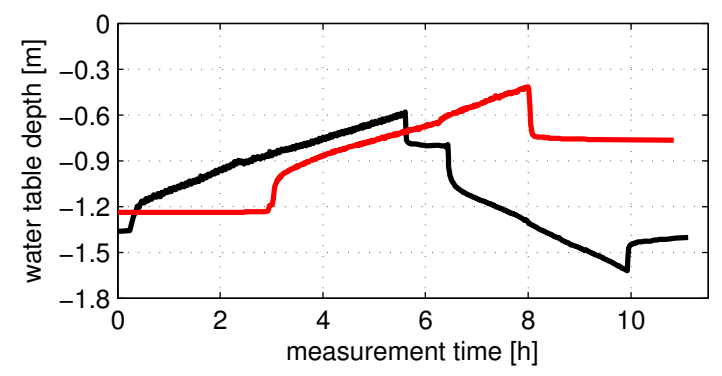

Figure 2. Variation of the water table depth below the surface over the course of experiments 1 (black line) and 2 (red line) as measured in the pumping well. The first radargrams in Figs. 6 and 10 have been acquired at time $t=0 \mathrm{~h}$.

infiltration front due to the coarse textured material and the imposed high infiltration flux. After $1.6 \mathrm{~h}$, having reached a steady state of gravitational flow into the structure, the infiltration was stopped and immediately followed by a $5 \mathrm{~h}$ period of imbibition of $9.1661 \pm 0.0001 \mathrm{~m}^{3}$ of water. Afterwards, GPR measurements were continued at minute resolution for another $1.5 \mathrm{~h}$ followed by half-hourly measurements for another $3 \mathrm{~h}$ in order to monitor the subsequent relaxation phase.

An overview of the water table position in the observation well during the different stages of both experiments can be found in Fig. 2. For periods of imbibition (between 0.3 and $5.6 \mathrm{~h}$ for experiment 1 and between 3.0 and $8.0 \mathrm{~h}$ for experiment 2 , respectively), the figure shows that the water table rise - as measured in the observation well - is not entirely constant, despite the approximately constant water flux into the well. In particular, at times when the water table in the sand structure crosses major layer boundaries, we observe changes in the increase rate of the water table (e.g., between 2.2 and $2.6 \mathrm{~h}$ for experiment 1 , corresponding to the water table crossing the layer boundary in the two-layered region). This effect can be explained by the differing hydraulic properties of the respective materials and the corresponding adaptation of the transition zone above the capillary fringe. We have observed this effect in the GPR data as well and will discuss it in more detail below. The infiltration phase which took place during experiment 2 did not lead to a measurable change in the water table position.

\subsection{GPR instrument setup and data acquisition}

Both experiments were monitored by high-resolution common offset (CO) measurements using surface coupled, multichannel GPR systems manufactured by Ingegneria dei Sistemi (IDS), Italy. For experiment 1, we used a system with a center frequency of $400 \mathrm{MHz}$ for data acquisition, measuring along the long axis of the site (in the direction of motion). This measurement setup is shown in the left sketch of Fig. 3. In this paper, we only discuss the data measured by the internal channel of the second antenna (T2R2) with an antenna separation of $d=0.14 \mathrm{~m}$.
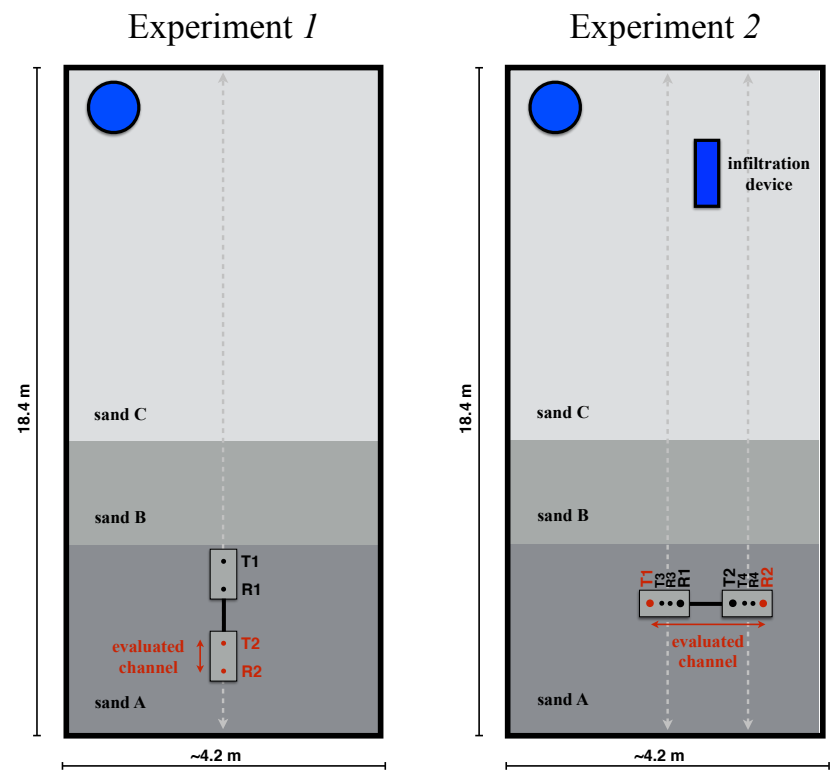

Figure 3. Overview of the measurement setup for both experiments. For experiment 1 (left side), four-channel GPR data were acquired at a center frequency of $400 \mathrm{MHz}$ along the center line of the structure, while water was pumped into and out of the observation well marked by the blue circle. For experiment 2 (right side), eightchannel dual-frequency $(200 / 600 \mathrm{MHz})$ data were acquired perpendicular to the direction of movement. The channel evaluated for this paper is specifically marked for both cases (experiment 1: T2R2; experiment 2: T1R2). Note that the aspect ratio of the figure does not correspond to reality.

For experiment 2 , a slightly different setup was chosen using two $200 / 600 \mathrm{MHz}$ dual-frequency antennas. In this case, the measurement direction is perpendicular to the direction of motion (along the short axis of the structure), as is shown in the right sketch of Fig. 3. This setup allows the cross-box channels to measure through the imposed infiltration front. From experiment 2, we will concentrate on discussing the phenomenology of the hydraulic dynamics as observed by one of the $200 \mathrm{MHz}$ cross-box channels (T1R2) with an antenna separation of $d=1.44 \mathrm{~m}$.

During experiment $1, \mathrm{CO}$ radargrams were acquired between 6 and $19 \mathrm{~m}$ at minute resolution. Every $10 \mathrm{~min}$, the measurement was extended to cover the whole distance. For experiment 2, radargrams covering the whole length of the ASSESS site were acquired at approximately one CO radargram per minute.

\subsection{Data processing and modeling}

GPR data were subjected to a standard dewow filter removing low-frequency noise. For better visibility of fainter features, a linearly increasing gain was applied. Unless noted otherwise, all radargrams have been subjected to the same post-processing in order to allow for direct comparison. For better illustration of the observed hydraulic dynamics, time- 
lapse movies have been produced for both experiments based on the minute-resolution radargrams acquired in each case.

To calculate average dielectric permittivities from the bottom reflection, time zero calibration was executed by measuring the travel time of the GPR signal in the air. Absolute travel times were then evaluated along each radargram using a semi-automated picking algorithm, following the central minimum of the bottom reflection from each trace to the next. Calculated bulk permittivities $\epsilon_{\mathrm{b}}(-)$ were converted to water contents $\theta(-)$ using the complex-refractive index model (CRIM, e.g., Birchak et al., 1974; Roth et al., 1990)

$\theta=\frac{1}{\sqrt{\epsilon_{\mathrm{w}}}-1} \sqrt{\epsilon_{\mathrm{b}}}-\frac{(1-\phi) \sqrt{\epsilon_{\mathrm{s}}}+\phi}{\sqrt{\epsilon_{\mathrm{w}}}-1}$,

which is essentially a linear relationship as a function of $\sqrt{\epsilon_{\mathrm{b}}}$. We employ $\epsilon_{\mathrm{s}}=5$ for the relative dielectric permittivity of the soil matrix based on available literature values (e.g., Daniels, 2004; Robinson, 2004). The soil porosity $\phi(-)$ has been estimated from gravimetric sampling during the building process of the ASSESS site.

Hydraulic simulations of soil water content dynamics were based on $\mu \phi$ (MuPhi, Ippisch et al., 2006). As detailed in the following section, we have used a Brooks-Corey parameterization for the soil water characteristic. All corresponding parameters for the different modeling cases presented in this study are given in Table 1 . Simulated water content distributions were converted to dielectric permittivity based on the CRIM. GPR responses are then modeled by 2-D simulations with the FDTD-based code MEEP (Oskooi et al., 2010) using a Ricker source current excitation and assuming a negligible electric conductivity of the subsurface.

\section{Phenomenology of the capillary fringe reflection}

\subsection{Theoretical considerations}

Soil water flow in the vadose zone is described using the Richards equation, combining the conservation of volume with the empirical Buckingham-Darcy flux law (Richards, 1931):

$\partial_{t} \theta\left(h_{\mathrm{m}}\right)-\nabla \cdot\left[K_{\mathrm{w}}\left(\theta\left(h_{\mathrm{m}}\right)\right)\left[\nabla h_{\mathrm{m}}-1\right]\right]=0$,

where $\theta(-)$ designates the volumetric soil water content and $K_{\mathrm{W}}\left(\mathrm{m} \mathrm{s}^{-1}\right)$ the hydraulic conductivity, assuming an isotropic medium. Furthermore, $h_{\mathrm{m}}=\Psi_{\mathrm{m}} / \rho_{\mathrm{w}} g$ denotes the matric head $(\mathrm{m})$, where $\Psi_{\mathrm{m}}\left(\mathrm{J} \mathrm{m}^{-3}\right)$ is the soil matric potential, $\rho_{\mathrm{w}}$ $\left(\mathrm{kg} \mathrm{m}^{-3}\right)$ the water density and $g\left(\mathrm{~m} \mathrm{~s}^{-2}\right)$ the gravitational acceleration. In static equilibrium, the matric head describes the negative height above a certain reference height $z_{0}(\mathrm{~m})$ for the corresponding potential $\Psi_{\mathrm{m}}$. In this case and for $z_{0}=0$ at the position of the water table, $h_{\mathrm{m}}=-z$, which allows one to directly associate the matric head with heights above a water table in hydraulic equilibrium.
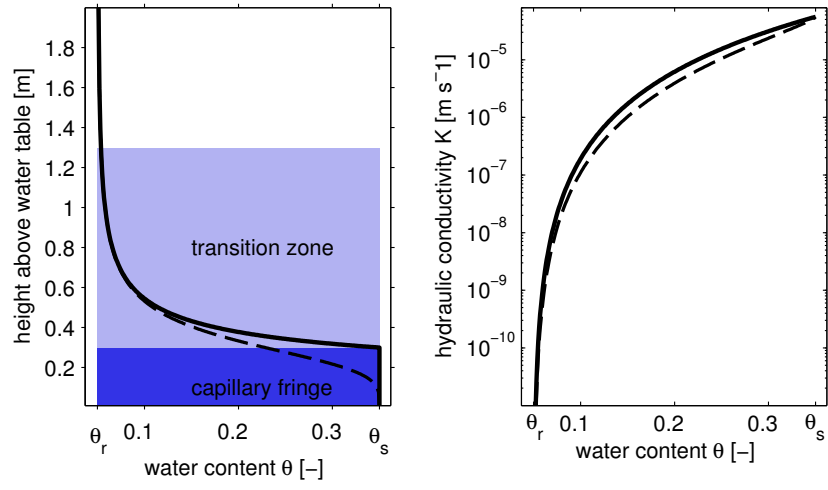

Figure 4. The sketch on the left shows the capillary fringe and the transition zone from saturated water content $\theta_{\mathrm{S}}$ to residual water content $\theta_{\mathrm{r}}$ above a water table for a generic coarse sand in equilibrium. The thick black line represents a Brooks-Corey parameterization of the soil water characteristic; the dashed black line denotes the soil water characteristic using the corresponding simplified Mualem-van Genuchten parameterization for the same sand. The diagram on the right shows the corresponding hydraulic conductivity functions as a function of water content. Note the logarithmic scale of the ordinate. For a detailed overview of the parameters, refer to Table 1 .

Due to the strong dependency of $\theta$ on the matric head $h_{\mathrm{m}}$, constitutive relationships are needed in order to solve Eq. (2) for water content dynamics, namely the hydraulic conductivity function $K_{\mathrm{w}}\left(h_{\mathrm{m}}\right)$ and the relation between the soil matric head and the soil water content $\theta\left(h_{\mathrm{m}}\right)$, the so-called soil water characteristic. The most widely employed models for these two functional relationships are the Mualemvan Genuchten and Mualem-Brooks-Corey models, which are most conveniently formulated in terms of the water saturation $\Theta(-)$. For the soil water characteristic, the most commonly applied models are the Brooks-Corey parameterization (Brooks, 1966), the van Genuchten parameterization and a simplified version of the latter (Van Genuchten, 1980). The Brooks-Corey parameterization, for example, is given by

$\Theta\left(h_{\mathrm{m}}\right)= \begin{cases}{\left[-\frac{h_{\mathrm{m}}}{h_{0}}\right]^{-\lambda} ;} & -h_{\mathrm{m}}>h_{0} \\ 1 ; & -h_{\mathrm{m}}<h_{0}\end{cases}$

with the air entry value $h_{0}>0(\mathrm{~m})$ and the shape parameter $\lambda(-)$. The left plot in Fig. 4 illustrates its inverse function, which is defined for $\Theta<1$ as

$h_{\mathrm{m}}(\Theta)=-h_{0} \Theta^{-\frac{1}{\lambda}}$,

under equilibrium conditions in terms of the height above a water table for a generic coarse sand (see Table 1). In particular, the figure shows the capillary fringe (which we define in this context as the region in which the soil stays completely saturated due to capillary forces, despite an already negative potential) and its associated transition zone from saturated water content $\theta_{\mathrm{s}}$ to residual water content $\theta_{\mathrm{r}}$ above a wa- 
ter table. For comparison, Fig. 4 also contains the soil water characteristic for the same sand using the corresponding simplified van Genuchten parameterization. For both parameterizations, the soil water characteristic describes a smooth water content transition above a water table for a certain hydraulic state in a homogeneous material. Such a water content transition corresponds to a gradual dielectric permittivity variation with depth (the corresponding permittivity profile can be calculated by employing an appropriate petrophysical relationship such as the CRIM; see Eq. 1). Hence, we can expect a corresponding GPR response from these permittivity variations, as has been shown by Dagenbach et al. (2013). For simplicity, we will denote this GPR response as the capillary fringe reflection (CFR), noting that this reflection in fact comprises the coherent superposition of all infinitesimal contributions along the whole transition zone above the water table. As an interference phenomenon, the resulting CFR will be sensitive to the specific shape of this transition zone. Hence, information about both the hydraulic state and the hydraulic properties can be gained from observing the CFR with GPR.

As can be seen from Fig. 4, the Brooks-Corey and van Genuchten parameterizations differ most significantly close to saturation, where the simplified van Genuchten parameterization is smooth without a well-defined capillary fringe, while the Brooks-Corey formulation has a sharp air entry value. Following Dagenbach et al. (2013), a Brooks-Coreytype parameterization with respect to this sharp air entry value is needed to describe the shape of the transition zone in materials with a narrow pore size distribution in order to reproduce the characteristics of the measured GPR response. In the framework of this study, we will therefore directly employ a Brooks-Corey parameterization for the soil water characteristic, noting in passing that a sharp air entry value could also be realized using an appropriate full van Genuchten formulation.

For completeness, the functional relationship for the hydraulic conductivity function $K_{\mathrm{w}}(\Theta)$ is given in terms of the water saturation by Mualem, 1976:

$$
K_{\mathrm{W}}(\Theta)=K_{\mathrm{s}} \Theta^{\tau}\left[\frac{\int_{0}^{\Theta} h_{\mathrm{m}}(\vartheta)^{-1} \mathrm{~d} \vartheta}{\int_{0}^{1} h_{\mathrm{m}}(\vartheta)^{-1} \mathrm{~d} \vartheta}\right]^{2},
$$

introducing two additional parameters. Here, $K_{\mathrm{S}}$ is the saturated hydraulic conductivity. The term $\Theta^{\tau}(-)$ is a measure of the tortuosity of the considered porous medium, acknowledging a strong dependency of the hydraulic conductivity function on the geometry of the pore space. Most often, $\tau(-)$ is simply treated as an additional fit parameter. Equation (5) shows that the shape of $K_{\mathrm{w}}(\Theta)$ depends on the choice of parameterization for the soil water characteristic, which is illustrated in the plot on the right side of Fig. 4. Note that the hydraulic conductivity varies over several orders of magnitude with water content. This highly non-linear behavior leads to characteristic deformations of the transition zone shape under the transient conditions imposed in our experiments as discussed below.

\subsection{Numerical simulation}

Before we turn to the experimental data, we will now take a phenomenological look at numerical simulations of the GPR response to different hydraulic states of the capillary fringe in a generic coarse sand (compare Table 1) as illustrated in Fig. 5. The top three plots show the shape of the transition zone above the capillary fringe in homogeneous sand for the different hydraulic regimes encountered in experiment 1 . The corresponding modeled GPR responses for each regime are shown in the lower part of the figure.

In hydrostatic equilibrium (black line in plot i), the CFR displays two distinct features: a maximum-minimum shape (black line in plot iv). The most notable contribution to the signal in this case stems from the region around the kink just above the capillary fringe, where the permittivity change with depth is the largest.

Under transient conditions, the shape of the transition zone will change due to the strong non-linearities in the hydraulic conductivity function, which varies over several orders of magnitude. For imbibition, this leads to a sharpening of the transition zone (compare the red line in plot i) and most notably to a second kink in the dry region, in this case at about $1.6 \mathrm{~m}$ depth. This translates to overall increased amplitudes and a second major contribution to the GPR signal (red line in plot iv), which manifests as the CFR now clearly exhibiting properties of two superimposed wavelets.

During a relaxation phase following this period of imbibition, the transition zone will start to reequilibrate (from red to blue in plot ii), separating the two kinks in depth and reducing the steepness of the transition zone. Hence, the difference in the arrival times of the corresponding two major contributions to the CFR will increase, leading to a splitting of the superimposed wavelets and a slightly reduced amplitude (from red to blue in plot v). Pumping the water out again will lead to a greatly elongated shape of the transition zone above the capillary fringe, while the dry end kink does not vanish completely, since equilibration times are increasingly slow in the dry regime (from blue to green in plot iii). Hence, the CFR exhibits much lower amplitudes and a small wavelet contribution slowly fading away at short travel times (corresponding to the slowly diminishing dry end kink), while the second contribution from the top of the capillary fringe starts to resemble the equilibrium wavelet again (from blue to green in plot vi; compare the latter with the black line in plot iv).

In summary, we can expect that the CFR will change its shape under transient conditions according to different hydraulic states: for a period of imbibition followed by brief relaxation and subsequent drainage, we expect an intensifying 

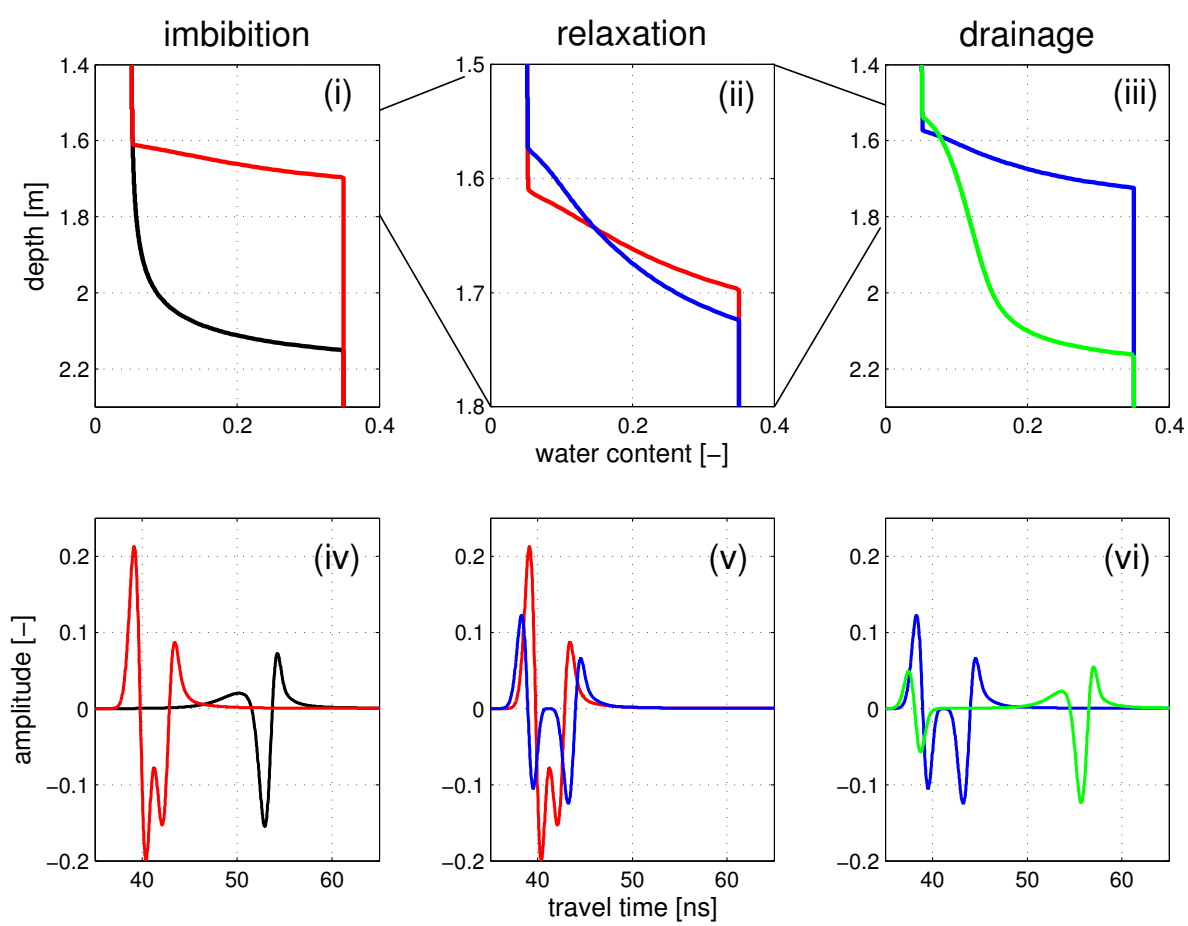

Figure 5. The capillary fringe reflection: distinct hydraulic states (i-iii) for imbibition, relaxation and pumping out as well as the expected corresponding GPR response (iv-vi). The hydraulic dynamics have been modeled for a typical coarse sand using a similar forcing as in experiment 1. Employed hydraulic parameters can be found in Table 1.

CFR signal and the advent of additional contributions to the CFR during imbibition, a splitting of these contributions during relaxation, and a much fainter response during drainage.

\section{Experimental results and discussion}

In this section, we will take a close look at the experimental results from the two experiments. We will first discuss the phenomenology of the CFR in light of the expectations detailed in the previous paragraphs and will then turn to quantitative monitoring of water content changes. For both experiments, we base our discussion of the observed phenomenology on a series of characteristic radargrams selected from each experiment's time series. Moreover, a time-lapse movie has been produced from all minute-resolution radargrams for both experiments, in order to better illustrate the observed effects. Alongside the time-lapse radargrams, the movies feature time-lapse representations of traces recorded at two characteristic locations during each experiment. These locations are designated in the radargrams by color-coded arrows. Both movies have been published in the Supplement to this study. A corresponding URL can be found at the end of this paper.

\subsection{Experiment 1: phenomenology}

The state of the system as imaged by GPR at different characteristic times of experiment 1 is illustrated in the eight radargrams shown in Fig. 6. The first radargram was acquired immediately before the start of the experiment. Apart from the three-featured (red-blue-red or blue-redblue) wavelets stemming from layer boundary reflections, the CFR is present as a distinct two-feature (red-blue) wavelet recorded at arrival times around $23 \mathrm{~ns}$ throughout the subsurface structure, as we would expect for a well-equilibrated situation (compare the black wavelet in part (iv) of Fig. 5). $15 \mathrm{~min}$ after the start of the imbibition phase (radargram 2), the CFR already starts to move towards shorter travel times. With a continuously increasing water potential through this imbibition, the overall water content in the subsurface increases, as corroborated by the bottom reflection arrival moving to longer travel times (see radargrams 2-5). As expected, the CFR wavelet changes in shape, while its amplitude increases considerably. During the ensuing equilibration phase, we notice that the CFR signal splits into two distinct twofeatured wavelets (compare radargrams 5 and 6). During the drainage process, the CFR can still be discerned, but it is much fainter (compare, e.g., the signals within the black rectangles in radargrams 3 and 7 that are acquired in roughly the same water table position). These effects can be observed even more clearly in the time-lapse movie "Klenke- 

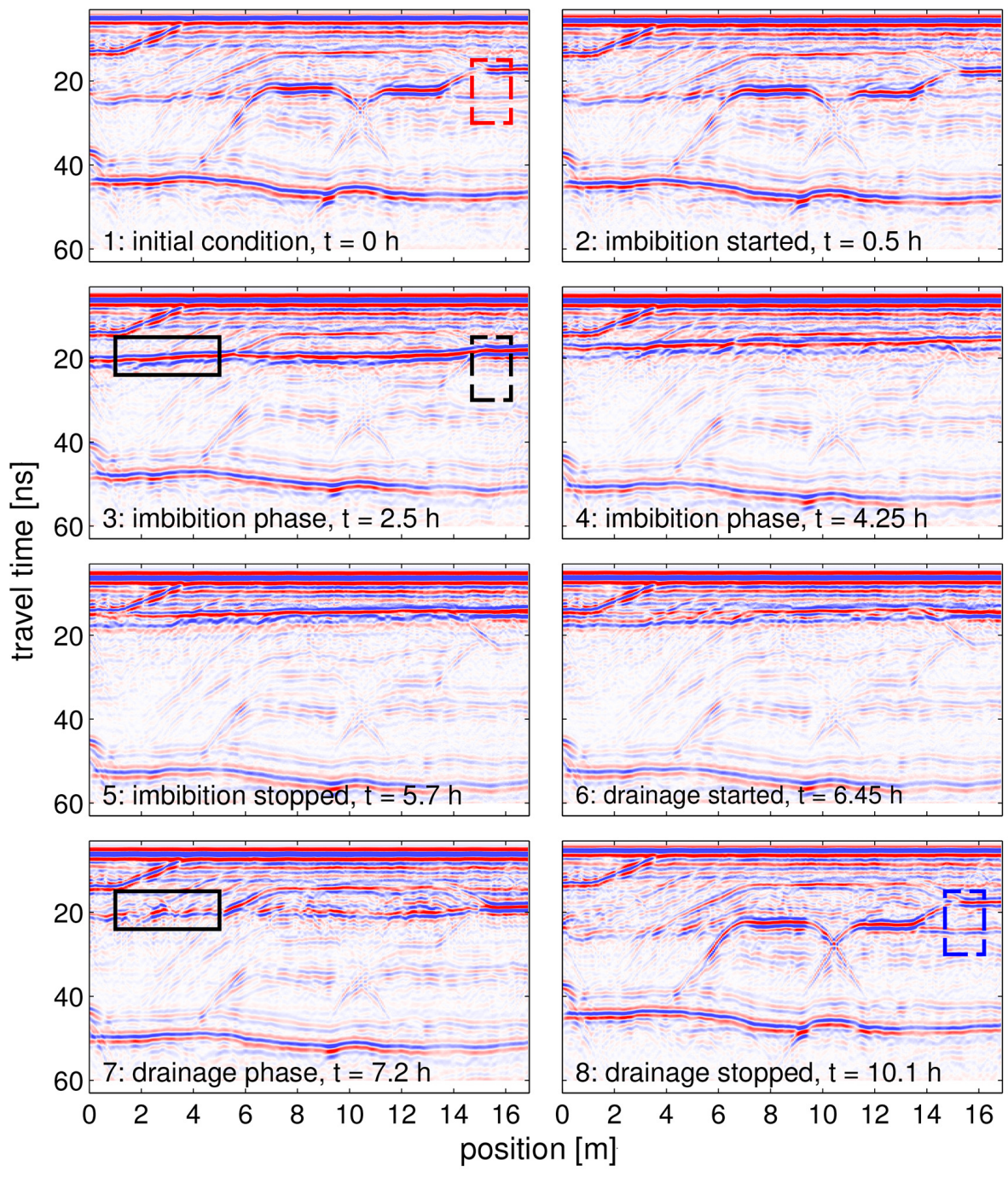

Figure 6. Common offset radargrams showing the hydraulic state during experiment 1 (imbibition/relaxation/drainage) at several characteristic times. The solid black rectangles in radargrams 3 and 7 mark the CFR at approximately the same position during imbibition and drainage, respectively. The dashed rectangles in radargrams 1, 3 and 8 denote the regions over which the traces shown in Fig. 7 are averaged.

tal_HESS+2015_Exp1_movie.mp4”, which is published in the Supplement to this study. Looking in more detail at the relative position and shape of the CFR, the radargrams also show some differences between the separate subsurface materials during the imbibition phase. These differences are attributed to differences in the respective hydraulic properties that become evident in this highly dynamic process.

\subsection{Experiment 1: sensitivity to higher-order structural elements}

Apart from layer boundary reflections and the CFR, additional signals can be discerned, depending on the specific hydrologic state. For example, comparing the radargrams acquired before and after the experiment (radargrams 1 and 8) for positions between 14 and $16 \mathrm{~m}$ (the two-layered part of the structure), there is an additional notable reflection arriving at travel times around $23 \mathrm{~ns}$ whenever the water table position is just below. In order to examine the behavior of this reflection in more detail, Fig. 7 shows traces averaged over the regions marked by the corresponding colored dashed rectangles in Fig. 6. The additional reflection is drawn as thick red and blue lines in Fig. 7 for the two cases in which it is clearly discernible. This reflection does not arise at a conventional layer boundary between different kinds of sand, but is due to the building process of our site, during which the sands had to be compacted at regular intervals. This compaction process of the sand material altered the pore geometry below each compaction horizon. The associated reorganization of the grains leads to a local porosity variation and concomitantly to a higher capillary rise within the material just below such a compaction horizon. Hence, whenever the 
Table 1. Brooks-Corey parameters used for modeling soil hydraulic dynamics.

\begin{tabular}{lcccccc}
\hline Parameter & $h_{0}(\mathrm{~m})$ & $\lambda(-)$ & $\phi(-)$ & $\theta_{\mathrm{r}}$ & $K_{\mathrm{S}}\left(\mathrm{m} \mathrm{s}^{-1}\right)$ & $\tau(-)$ \\
\hline Figures 4 and 5 (generic coarse sand) & 0.30 & 3.00 & 0.35 & 0.05 & $5.6 \times 10^{-5}$ & 0.5 \\
ASSESS sand A & 0.11 & 0.99 & 0.38 & 0.01 & $1.0 \times 10^{-4}$ & 0.5 \\
ASSESS sand C & 0.08 & 1.70 & 0.35 & 0.00 & $8.4 \times 10^{-5}$ & 0.5 \\
\hline
\end{tabular}

water table position is just below a compaction horizon, there is a significant dielectric contrast over this horizon, leading to the observed reflected signal. Here, this is the case for the hydrologic states observed both before (trace from radargram 1, drawn in red) and after (trace from radargram 8, drawn in blue) the experiment. In the fully saturated case (trace from radargram 3 , drawn in black), the remaining permittivity contrast is solely due to differences in porosity, which are here not large enough to lead to a notable response. The different shapes of the red and blue wavelets are due to additional contributions to the signal from the region above the compaction layer after it has been wetted during the experiment.

In our case, these local variations within the same material are an artifact of the building process. Nevertheless, similar situations may arise in field data sets and the appearance of such a reflection according to the respective hydraulic state should instigate a careful interpretation of single-instant field data sets in which such a reflection may have easily been misinterpreted as a conventional layer boundary between potentially different materials. On the upside, close scrutiny of the temporal evolution of such a signal with the observed hydrologic state may yield valuable information about the underlying physical processes.

\subsection{Experiment 1: high-precision water content changes}

Evaluating the bottom reflection travel time for permittivities, we can calculate the average water content change over time along the whole structure. For clarity, we will here only illustrate averaged results for two distinct regions. Figure 8a shows a comparison of the water content change for the twolayered part and Fig. 8b the corresponding result around the synclinal structure (red rectangles in Fig. 1a). Keeping in mind that each black data point represents an averaged value taken from a different common offset measurement, the precision for measuring the total water content change is very high. In fact, the two figures show that we achieve a sensitivity better than $0.001 \mathrm{~m}^{3} \mathrm{~m}^{-3}$ for measuring these water content changes.

Looking first at the water content dynamics for the twolayered region (Fig. 8a), we see during both imbibition and drainage that the water content change slows down considerably when the capillary fringe crosses the layer boundary. This happens for the imbibition between 2.5 and $4 \mathrm{~h}$ as well as during the drainage between 8 and $9 \mathrm{~h}$ (as marked

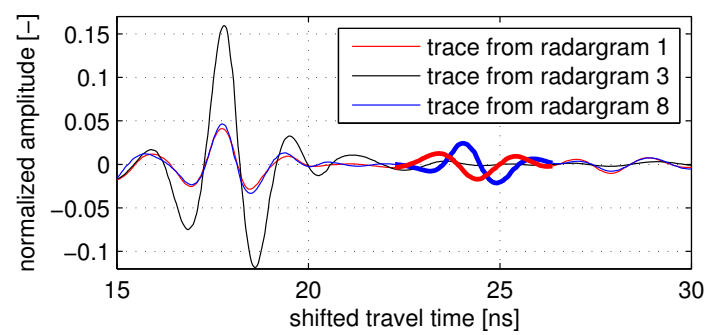

Figure 7. Detailed view of the compaction layer reflection. The traces shown have been averaged over the regions, which are marked by correspondingly colored rectangles in Fig. 6 (radargrams 1, 3 and 8). The traces have been referenced to the central maximum feature of the first layer reflection (illustrated at travel times between 15 and $20 \mathrm{~ns}$ ). The respective compaction layer reflection wavelets are drawn with thick lines where they can be discerned (radargrams 1 and 8). For radargram 3 (water table coincides with the first layer reflection), the compaction layer does not yield a clearly discernible reflected wavelet due to the much smaller permittivity contrast in this fully saturated case.

by the yellow shaded rectangle in the figure). This observation can be explained in terms of the different hydraulic properties of the two sands in this part of the structure. In our experiment, imbibition results from an approximately constant water flux into the observation well, which is distributed over the lower boundary by a gravel layer with high hydraulic conductivity. Under transient conditions, the dynamic shape of the imbibition-induced invading front at each position is governed by the local water flux and the respective hydraulic properties, especially the non-linearities of the hydraulic conductivity function, which typically varies over several orders of magnitude (compare the plot on the right of Fig. 4). This is illustrated in Fig. 9, illustrating the transient shape of a dynamically varying transition zone above a capillary fringe for a two-layered medium consisting of ASSESS sands A (lower layer) and C (upper layer) when subjected to the imbibition forcing of experiment 1 . The figure shows the equilibrium curve prior to imbibition (solid black line), transient shapes of the transition zone in $0.2 \mathrm{~h}$ intervals during imbibition (dashed grey lines) and the transient shape at the end of the imbibition process (solid blue line). Comparing the grey shaded areas, which denote imbibition intervals of equal length, the figure shows that the transition zone develops a quasi-stationary dynamic shape. Assuming a homogeneous material sufficiently far from the 

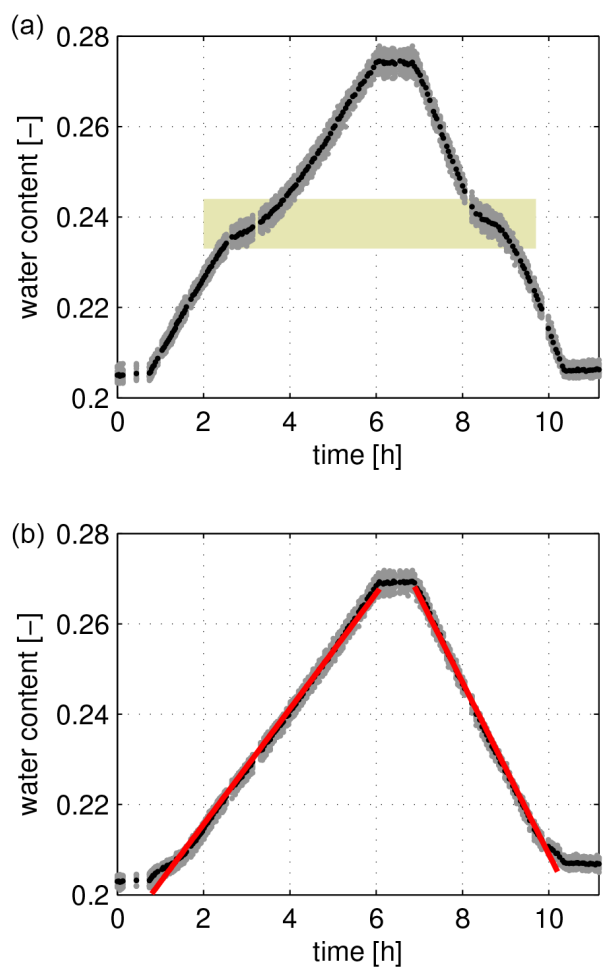

Figure 8. (a) Soil water content calculated from the bottom reflection travel time during experiment 1 in the two-layered region. The black dots denote results averaged over a $2 \mathrm{~m}$ stretch of the twolayered region (as indicated in Fig. 1), and the grey dots show all values measured along this stretch. The yellow shaded area denotes the water content change during time intervals in which the capillary fringe adapts while crossing the material boundary. This behavior is illustrated for the imbibition branch in Fig. 9. (b) Soil water content calculated from the bottom reflection travel time during experiment 1 in the region of the synclinal structure. The black dots denote results averaged over a $2 \mathrm{~m}$ stretch in this region (as indicated in Fig. 1), and the grey dots show all values measured along this stretch. The red lines indicate a linear fit to the imbibition and drainage branches of the averaged soil water dynamics.

interface, this dynamic shape will vary only slowly while the water table moves towards the layer boundary at an approximately constant rate, leading to a correspondingly almost constant increase rate of soil water content. However, close to the layer boundary, the shape of the transition zone will have to adapt accordingly. This leads to a comparatively fast transitional process whose details are determined by the relative differences of the hydraulic properties of the two materials. Once the whole transition zone shape has been adapted (i.e., the transition zone has moved completely to the second material), the water content will again increase at a constant rate, given that the imbibition flux stays constant (compare the blue shaded areas). A differing water content increase rate in the two materials will be governed by differences of the respective hydraulic conductivity functions and potential porosity differences. This explains, e.g., the different slopes

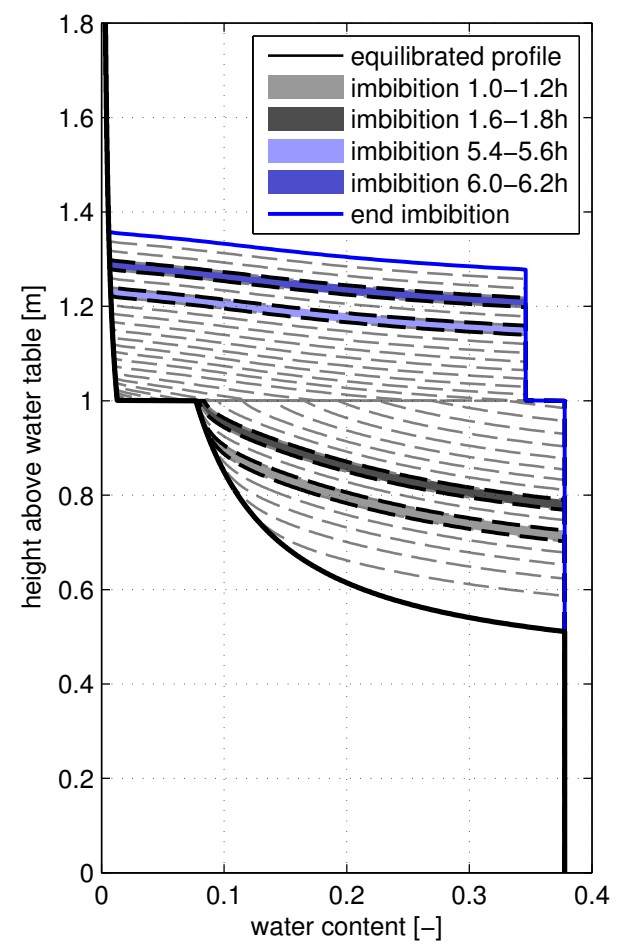

Figure 9. Transient shape of a dynamically varying transition zone above a capillary fringe for a two-layered medium consisting of ASSESS sands A (lower layer) and C (upper layer) when subjected to the imbibition forcing of experiment 1 . The solid black line indicates the equilibrium curve; the solid blue line denotes the transient shape just after the imbibition has been stopped. During imbibition, the transient state is marked every $0.2 \mathrm{~h}$ by grey dashed lines. A comparison of the grey (blue) shaded areas denoting equal imbibition intervals in both materials shows that the water content increase will proceed at an approximately constant but potentially different rate in both materials sufficiently far from the interface. At the interface, the shape of the capillary fringe has to adapt, leading to a slower increase rate of the water content, as has been observed in Fig. 8.

of the water content increase observed with GPR in the experiment (compare the section between 1 and $2.5 \mathrm{~h}$ to the section between 4.5 and $6 \mathrm{~h}$ in Fig. 8a).

Similar arguments apply to the drainage part of the experiment. Hence, comparing the constant rate of increase (or decrease during drainage, respectively) of the overall water content while the transition zone moves entirely through one material gives access to relative differences in both the soil hydraulic conductivity function and the porosity of the two materials.

Turning to the diagram showing the water contents as derived over the synclinal structure, we see that, in this case, both the increasing and decreasing branch of the average water contents follow practically straight lines. This is to be expected if we again assume constant imbibition and drainage fluxes as well as an only slowly varying transient shape of 
the transition zone, since the capillary fringe does not cross any layer boundary at this position. Only at the very beginning and the very end are there slight deviations from this straight line. Here, the capillary fringe reaches the bottom of the synclinal structure, leading to the same implications as discussed above. Fitting straight lines to both branches (indicated as red lines in Fig. 8b), we can calculate the ratio of the their slopes to be 0.69 . This is in very good agreement with the ratio of the pumping rates of 0.70 , underlining the accuracy of monitoring soil water dynamics with GPR.

\subsection{Experiment 2: phenomenology}

The state of the system as imaged by the $200 \mathrm{MHz}$ crossbox channel ("T1R2" in the right plot of Fig. 3) at different characteristic times of experiment 2 is illustrated in the eight radargrams shown in Fig. 10. For a more detailed representation of the dynamics at the location of the infiltration pulse, refer to Fig. 11. The effects that are discussed in the following can also be observed in the time-lapse movie "Klenketal_HESS+2015_Exp2_movie.mp4", which is published in the Supplement to this study.

The first radargram in Fig. 10 shows the state of the system before the start of experiment 2 . The site is largely in equilibrium except for a region around $3.8 \mathrm{~m}$, where another infiltration experiment had taken place the day before. Due to the large fraction of fine grains in sand A, the topsoil remains pre-wetted in this region, as can be seen from the GPR signal. The CFR arrives at travel times around $20 \mathrm{~ns}$, which in equilibrium corresponds to a water table height in the observation well of $0.67 \mathrm{~m}$. Before acquiring radargram 2, a continuous infiltration pulse is applied around $17 \mathrm{~m}$, at the location that had been indicated in Fig. 3. Not surprisingly, the direct ground wave signal becomes apparent at a strongly increased amplitude and longer travel times due to the wetting of the top soil (marked by the black arrow in radargram 2). About $1 \mathrm{~h}$ into the infiltration experiment, the wetting front has reached the water table and a steady state infiltration regime (constant gravity flow) has established itself (radargram 3). Until the infiltration is stopped, the GPR response changes only slightly due to a minor horizontal widening of the infiltration pulse perpendicular to the infiltration direction. Immediately before acquiring radargram 4 , the infiltration had been stopped and we started the imbibition by pumping water into the observation well, in turn raising the water table in the structure. Correspondingly, the signal around the infiltration location starts to relax (i.e., the ground wave signal immediately responds to the dropping water content in the top soil), while the CFR (arriving around $20 \mathrm{~ns}$ ) starts to intensify, similar to the previous experiment. $1.8 \mathrm{~h}$ after starting the pumping process, we can observe again a splitting of the CFR reflection into two two-featured wavelets, moving synchronously with the rising water table to smaller travel times, where the top soil had not been pre-wetted (compare, e.g., the region marked by the solid black rectangle in radar- gram 5). In comparison, where the soil had been pre-wetted by infiltration, the signal does not split (compare the region marked by the dashed black rectangle in radargram 5). We will have a closer look at this phenomenon below. The CFR signal recompresses to a three-featured wavelet at the layer boundary between sands $\mathrm{B}$ and $\mathrm{C}$ at $0.6 \mathrm{~m}$ depth. The imbibition was stopped just after the water table had risen above this layer boundary, allowing for comparison of the relaxation process in sand $\mathrm{C}$ for a pre-wetted region (around $17 \mathrm{~m}$ ) and a previously dry region $(6-14 \mathrm{~m})$. In the previously dry region, we observe that, as in the previous experiment, the portion of the CFR signal stemming from the non-equilibrium dry-region kink slowly disappears, leading to a similar relaxation behavior as discussed for experiment 1 (radargrams 6 to 7). In comparison, the CFR signal shape for the pre-wetted regime stays approximately unchanged, even until the following day (radargram 8).

This behavior is to be expected, since the highly non-linear hydraulic conductivity function (compare Fig. 4) leads to a much less pronounced sharpening of the capillary fringe in the pre-wetted case. This can be illustrated nicely through numerical modeling, as is shown in Fig. 12. We simulated here the GPR response of the CFR when applying the forcing of experiment 2 to a homogeneous 1-D sand profile with parameters of material C (Table 1). In Fig. 12, we compare the GPR response for the CFR in this sand for the case where the imbibition starts into a dry sand column (the top part of the figure, marked "imbibition only") to the GPR response for the pre-wetted case (the lower part of the figure, marked "imbibition after infiltration"), in which the imbibition starts after having applied an infiltration flux comparable to the experiment $\left(3.6 \mathrm{~mm} \mathrm{~h}^{-1}\right.$ for $2 \mathrm{~h}$ ).

The top left part of the figure illustrates the hydraulic dynamics for $5 \mathrm{~h}$ imbibition into the initially dry sand, followed by a relaxation period of $3 \mathrm{~h}$. In this case, the equilibrated capillary fringe (black line) sharpens (red line), which leads to a secondary kink in the dry region, and then relaxes (green line) under the imposed forcing. On the top right, we observe the corresponding CFR behavior (the wavelets have been shifted to coincide at the minimum of the CFR for clarity of representation): the CFR exhibits a pronounced change from the initially equilibrated case (black line) to the twowavelet response due to the emerging dry end kink (red line), and then back to the rather equilibrated behavior after $3 \mathrm{~h}$ of relaxation (green line), which almost coincides with the initial case.

In contrast, the bottom left part shows the hydraulic dynamics with the initial infiltration, adding an infiltration front (blue line) to the initially equilibrated state (black line, as before). Due to this pre-wetting before starting the imbibition, the hydraulic conductivity in the whole soil profile is much higher, leading to a much less pronounced sharpening of the capillary fringe during imbibition (from blue to red). Also, the shape of the capillary fringe changes only slightly during the equilibration phase (from red to green). As we have ob- 

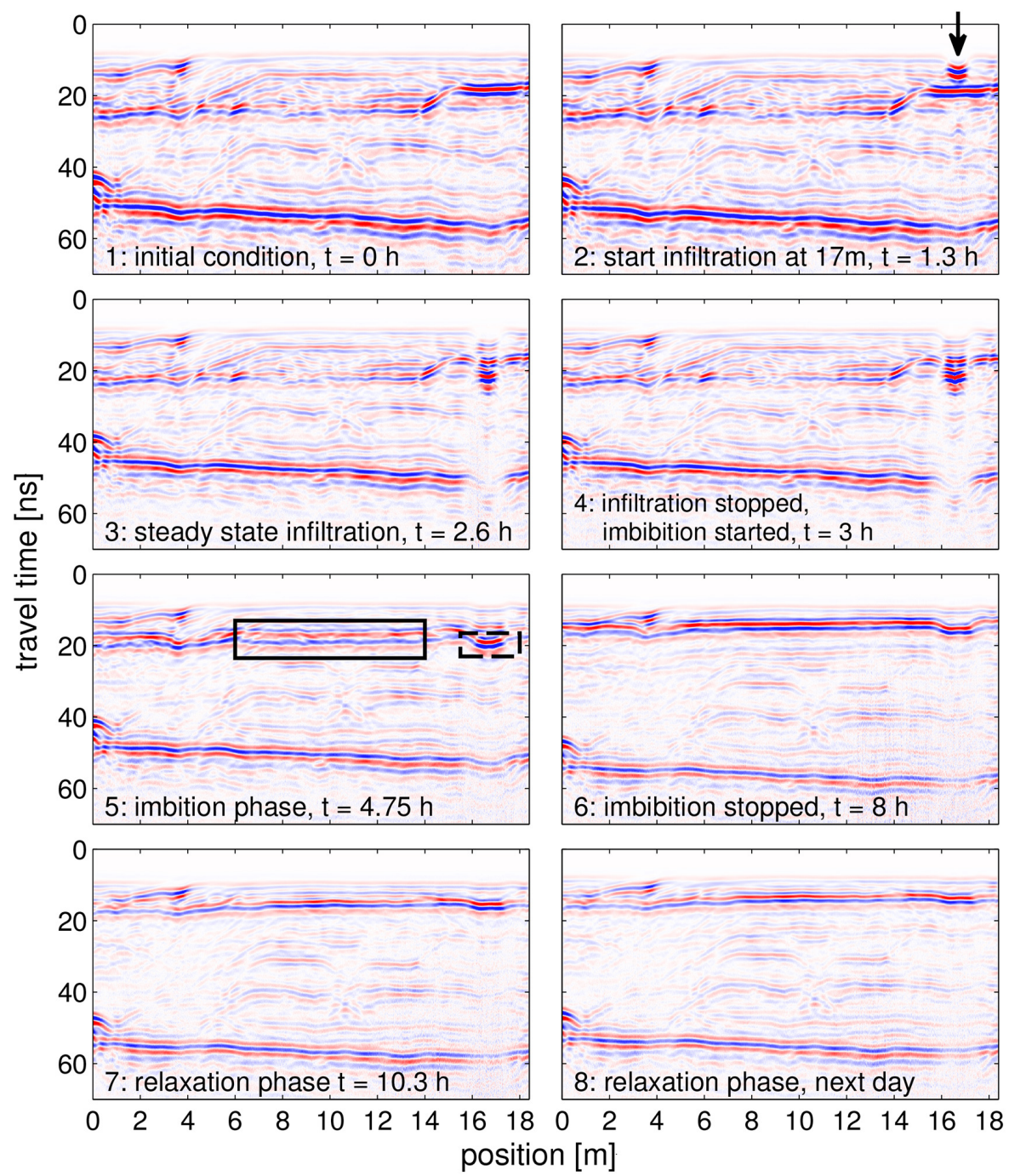

Figure 10. Common offset radargrams showing the hydraulic state of experiment 2 at several characteristic times: localized infiltration at $17 \mathrm{~m}$ (denoted by the black arrow in radargram 2) followed by imbibition and a period of relaxation. The dashed (solid) black rectangle in radargram 5 highlights the CFR in a (non) pre-wetted position during the imbibition phase.

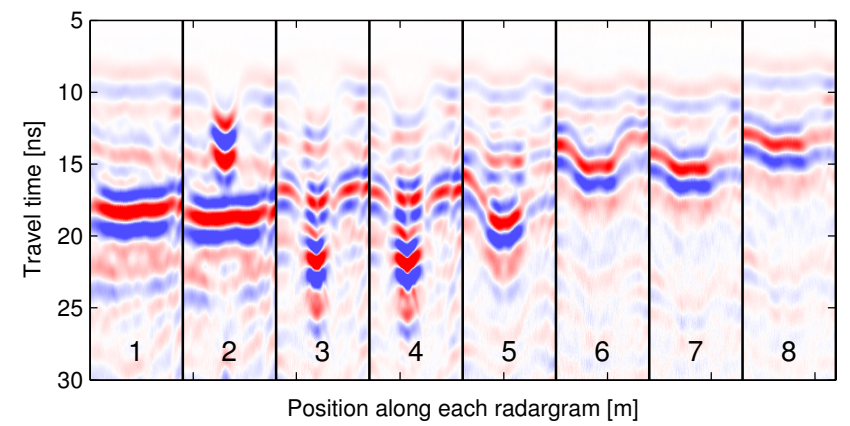

Figure 11. Excerpts from the eight radargrams in Fig. 10 to highlight the infiltration process during experiment 2. Each part shows the same $3 \mathrm{~m}$ stretch centered around $17 \mathrm{~m}$. served in the experiment, this leads to comparatively small changes to the CFR during the whole process (lower right part of Fig. 12).

\section{Summary and conclusions}

We explored several aspects of high-resolution time-lapse GPR observations of soil water dynamics with the aim of accessing information about field-scale soil hydraulic properties in a non-invasive manner. Two experiments have been carried out, in which we observed imbibition, infiltration and drainage into and out of a complicated but well-known subsurface structure by on-ground GPR. Two main aspects have been assessed: (i) the accurate determination of soil water dynamics averaged over the whole vertical extent by evaluating 

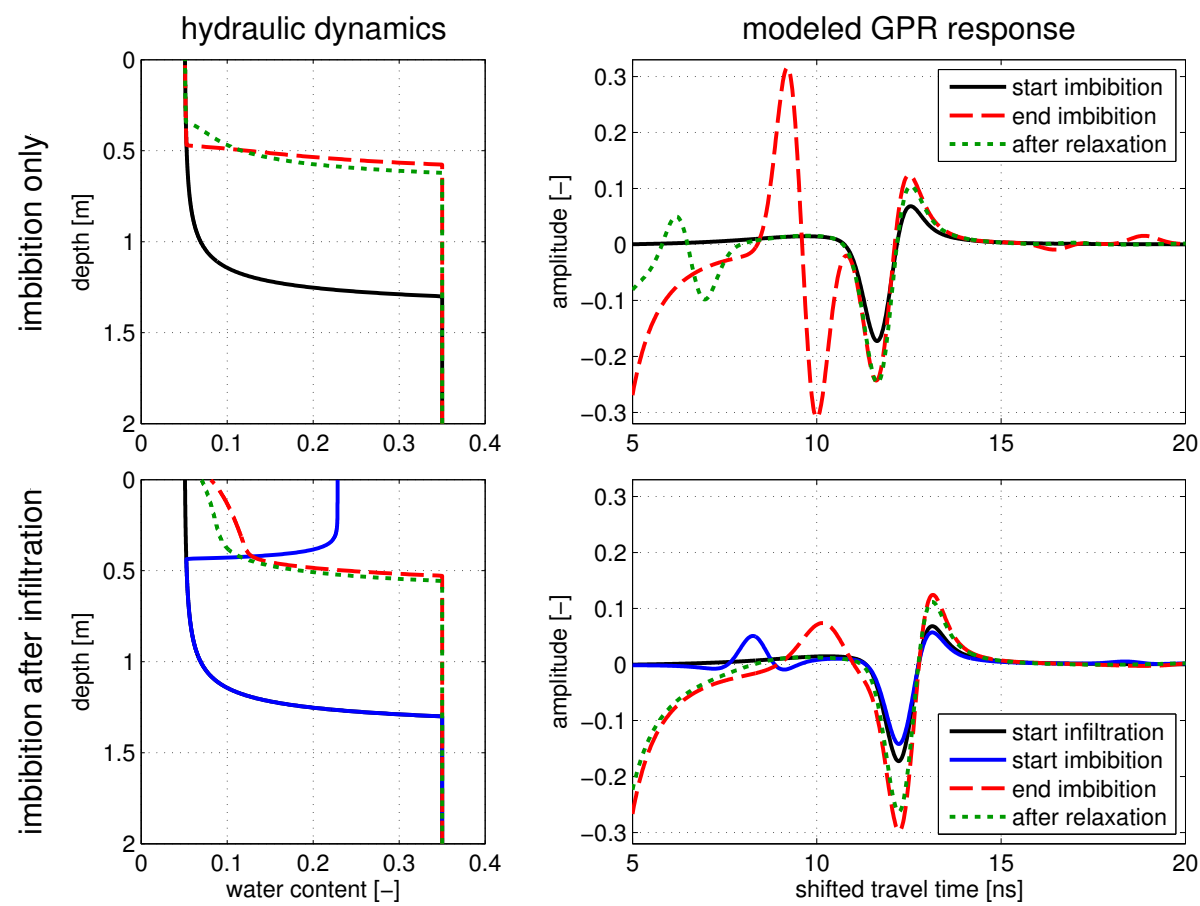

Figure 12. Comparing hydraulic dynamics (left panels) and the corresponding CFR GPR response (right panels) of a modeled 1-D sand Cprofile subjected to imbibition into dry sand followed by a period of relaxation (top panels) and the same imbibition after an additional infiltration event, pre-wetting the sand (bottom panels). For clarity, the GPR wavelets have been shifted to coincide at the minimum feature of the equilibrium CFR. Direct waves and the additional wetting front reflection in the pre-wetted case (arriving at travel times between 0 and $5 \mathrm{~ns}$ ) are not shown for clarity.

the bottom reflection and (ii) the feasibility of monitoring the dynamic shape of the capillary fringe reflection, a reflection generated by the transition zone above a water table.

We have shown that the precision of GPR measurements of soil water dynamics in this well-controlled experiment is about an order of magnitude better than demonstrated so far in the field, even without highly involved inversion schemes. Evaluation of the bottom reflection allows one to infer information about potentially complicated processes in the soil above and yields information about the relative hydraulic properties of the respective materials.

Secondly, the deformation and relaxation of the capillary fringe as observed by GPR under our imposed forcing corroborated our numerical simulations. Since the capillary fringe reflection arises as an interference phenomenon, its detailed shape under the forcing imposed for this study is very sensitive to the respective material properties. Hence, our high-resolution time-lapse observations pave the way for implementing appropriate schemes for in situ estimation of these properties based on GPR.

\section{The Supplement related to this article is available online at doi:10.5194/hess-19-1125-2015-supplement.}

Acknowledgements. We thank two anonymous reviewers for their time and their helpful suggestions for improving this manuscript and Hannes Bauser for proofreading. We acknowledge financial support by the Deutsche Forschungsgemeinschaft through project RO 1080/12-1 and the Deutsche Forschungsgemeinschaft and Ruprecht-Karls-Universität Heidelberg within the Open Access Publishing funding program.

Edited by: T. P. A. Ferre

\section{References}

Annan, A. P.: GPR Methods for Hydrogeological Studies, in: Hydrogeophysics, vol. 50 of Water Science and Technology Library, edited by Rubin, Y., Hubbard, S. S., and Singh, V., Springer Netherlands, Dordrecht, the Netherlands, 185-213, doi:10.1007/1-4020-3102-5, 2005.

Bano, M.: Effects of the transition zone above a water table on the reflection of GPR waves, Geophys. Res. Lett., 33, L13309, doi:10.1029/2006GL026158, 2006.

Bevan, M. J., Endres, A. L., Rudolph, D. L., and Parkin, G.: The non-invasive characterization of pumping-induced dewatering using ground penetrating radar, J. Hydrol., 281, 55-69, doi:10.1016/S0022-1694(03)00200-2, 2003.

Birchak, J. R., Gardner, C. G., Hipp, J. E., and Victor, J. M.: High dielectric constant microwave probes for sensing soil moisture, Proc. IEEE, 62, 93-98, doi:10.1109/PROC.1974.9388, 1974. 
Bogena, H. R., Herbst, M., Huisman, J. A., Rosenbaum, U., Weuthen, A., and Vereecken, H.: Potential of Wireless Sensor Networks for Measuring Soil Water Content Variability, Vadose Zone J., 9, 1002-1013, doi:10.2136/vzj2009.0173, 2010.

Bradford, J., Thoma, M., and Barrash, W.: Estimating hydrologic parameters from water table dynamics using coupled hydrologic and ground-penetrating radar inversion, in: Ground Penetrating Radar (GPR), 2014 15th International Conference on, 30 June4 July 2014, Brussels, Belgium, 232-237, 2014.

Brooks, R. H.: Properties of porous media affecting fluid flow, J. Irrig. Drain. Div., 92, 61-88, 1966.

Buchner, J. S., Wollschläger, U., and Roth, K.: Inverting surface GPR data using FDTD simulation and automatic detection of reflections to estimate subsurface water content and geometry, Geophysics, 77, H45-H55, doi:10.1190/geo2011-0467.1, 2012.

Busch, S., van der Kruk, J., Bikowski, J., and Vereecken, H.: Quantitative conductivity and permittivity estimation using fullwaveform inversion of on-ground GPR data, Geophysics, 77, H79-H91, doi:10.1190/geo2012-0045.1, 2012.

Busch, S., Weihermüller, L., Huisman, J. A., Steelman, C. M., Endres, A. L., Vereecken, H., and van der Kruk, J.: Coupled hydrogeophysical inversion of time-lapse surface GPR data to estimate hydraulic properties of a layered subsurface, Water Resour. Res., 49, 8480-8494, doi:10.1002/2013WR013992, 2013.

Busch, S., van der Kruk, J., and Vereecken, H.: Improved Characterization of Fine-Texture Soils Using On-Ground GPR FullWaveform Inversion, IEEE T. Geosci. Remote, 52, 3947-3958, doi:10.1109/TGRS.2013.2278297, 2014.

Dagenbach, A., Buchner, J. S., Klenk, P., and Roth, K.: Identifying a parameterisation of the soil water retention curve from onground GPR measurements, Hydrol. Earth Syst. Sci., 17, 611618, doi:10.5194/hess-17-611-2013, 2013.

Daniels, D. J.: Ground Penetrating Radar, chap. 4.3, The Institution of Electrical Engineers, London, UK, doi:10.1049/PBRA015E, 2004.

Doolittle, J. A., Jenkinson, B., Hopkins, D., Ulmer, M., and Tuttle, W.: Hydropedological investigations with ground-penetrating radar (GPR): Estimating water-table depths and local groundwater flow pattern in areas of coarse-textured soils, Geoderma, 131, 317-329, doi:10.1016/j.geoderma.2005.03.027, 2006.

Galagedara, L. W., Parkin, G. W., and Redman, J. D.: An analysis of the ground-penetrating radar direct ground wave method for soil water content measurement, Hydrol. Process., 17, 3615-3628, doi:10.1002/hyp.1351, 2003.

Gerhards, H., Wollschläger, U., Yu, Q., Schiwek, P., Pan, X., and Roth, K.: Continuous and simultaneous measurement of reflector depth and average soil-water content with multichannel ground-penetrating radar, Geophysics, 73, J15-J23, doi:10.1190/1.2943669, 2008.

Grote, K., Hubbard, S., and Rubin, Y.: Field-scale estimation of volumetric water content using ground-penetrating radar ground wave techniques, Water Resour. Res., 39, 1321, doi:10.1029/2003WR002045, 2003.

Huisman, J. A. and Bouten, W.: Accuracy and Reproducibility of Measuring Soil Water Content with the Ground Wave of GroundPenetrating Radar, J. Environ. Eng. Geophys., 8, 67-75, 2003.

Huisman, J. A., Hubbard, S. S., Redman, J. D., and Annan, A. P.: Measuring Soil Water Content with Ground Penetrating Radar: A Review, Vadose Zone J., 2, 476-491, 2003a.
Huisman, J. A., Snepvangers, J. J. J. C., Bouten, W., and Heuvelink, G. B. M.: Monitoring Temporal Development of Spatial Soil Water Content Variation: Comparison of Ground Penetrating Radar and Time Domain Reflectometry, Vadose Zone J., 2, 519-529, 2003b.

Ippisch, O., Vogel, H., and Bastian, P.: Validity limits for the van Genuchten-Mualem Model and implications for parameter estimation and numerical simulation, Adv. Water Resour., 29, 17801789, doi:10.1016/j.advwatres.2005.12.011, 2006.

Jadoon, K. Z., Slob, E., Vanclooster, M., Vereecken, H., and Lambot, S.: Uniqueness and stability analysis of hydrogeophysical inversion for time-lapse ground-penetrating radar estimates of shallow soil hydraulic properties, Water Resour. Res., 44, W09421, doi:10.1029/2007WR006639, 2008.

Jol, H. M. and Bristow, C. S.: GPR in sediments: advice on data collection, basic processing and interpretation, a good practice guide, Geol. Soc. Lond. Spec. Publ., 211, 9-27, doi:10.1144/GSL.SP.2001.211.01.02, 2003.

Klenk, P., Buchner, J., Roth, K., Wollschlager, U., Qin, Y., and Zhou, K.: On the reliability of current GPR ground wave methods for determining near-surface water contents, in: Advanced Ground Penetrating Radar (IWAGPR), 2011 6th International Workshop on, 22-24 June 2011, Aachen, Germany, 1-5, doi:10.1109/IWAGPR.2011.5963881, 2011.

Kowalsky, M. B., Finsterle, S., Peterson, J., Hubbard, S., Rubin, Y., Majer, E., Ward, A., and Gee, G.: Estimation of field-scale soil hydraulic and dielectric parameters through joint inversion of GPR and hydrological data, Water Resour. Res., 41, W11425, doi:10.1029/2005WR004237, 2005.

Lambot, S. and André, F.: Full-Wave Modeling of Near-Field Radar Data for Planar Layered Media Reconstruction, IEEE T. Geosci. Remote, 52, 2295-2303, doi:10.1109/TGRS.2013.2259243, 2014.

Lambot, S., Slob, E. C., van den Bosch, I., Stockbroeckx, B., Scheers, B., and Vanclooster, M.: Estimating soil electric properties from monostatic ground-penetrating radar signal inversion in the frequency domain, Water Resour. Res., 40, W04205, doi:10.1029/2003WR002095, 2004.

Lambot, S., Weihermüller, L., Huisman, J. A., Vereecken, H., Vanclooster, M., and Slob, E. C.: Analysis of airlaunched ground-penetrating radar techniques to measure the soil surface water content, Water Resour. Res., 42, W11403, doi:10.1029/2006WR005097, 2006.

Lambot, S., Slob, E., Rhebergen, J., Lopera, O., Jadoon, K. Z., and Vereecken, H.: Remote Estimation of the Hydraulic Properties of a Sand Using Full-Waveform Integrated Hydrogeophysical Inversion of Time-Lapse, Off-Ground GPR Data, Vadose Zone J., 8, 743-754, 2009.

Looms, M. C., Binley, A., Jensen, K. H., Nielsen, L., and Hansen, T. M.: Identifying Unsaturated Hydraulic Parameters Using an Integrated Data Fusion Approach on Cross-Borehole Geophysical Data, Vadose Zone J., 7, 238-248, 2008.

Minet, J., Wahyudi, A., Bogaert, P., Vanclooster, M., and Lambot, S.: Mapping shallow soil moisture profiles at the field scale using full-waveform inversion of ground penetrating radar data, Geoderma, 161, 225-237, doi:10.1016/j.geoderma.2010.12.023, 2011.

Minet, J., Bogaert, P., Vanclooster, M., and Lambot, S.: Validation of ground penetrating radar full-waveform inversion for 
field scale soil moisture mapping, J. Hydrol., 424-425, 112-123, doi:10.1016/j.jhydrol.2011.12.034, 2012.

Moysey, S. M.: Hydrologic trajectories in transient groundpenetrating-radar reflection data, Geophysics, 75, WA211WA219, 2010.

Mualem, Y.: A new model for predicting the hydraulic conductivity of unsaturated porous media, Water Resour. Res., 12, 513-522, doi:10.1029/WR012i003p00513, 1976.

Neal, A.: Ground-penetrating radar and its use in sedimentology: principles, problems and progress, Earth-Sci. Rev., 66, 261-330, doi:10.1016/j.earscirev.2004.01.004, 2004.

Oskooi, A. F., Roundy, D., Ibanescu, M., Bermel, P., Joannopoulos, J. D., and Johnson, S. G.: MEEP: A flexible freesoftware package for electromagnetic simulations by the FDTD method, Comput. Phys. Commun., 181, 687-702, doi:10.1016/j.cpc.2009.11.008, 2010.

Richards, L. A.: Capillary conduction of liquids through porous mediums, J. Appl. Phys., 1, 318-333, doi:10.1063/1.1745010, 1931.

Robinson, D. A.: Measurement of the solid dielectric permittivity of clay minerals and granular samples using a time domain reflectometry immersion method, Vadose Zone J., 3, 705-713, 2004.

Robinson, D. A., Jones, S. B., Wraith, J. M., Or, D., and Friedman, S. P.: A Review of Advances in Dielectric and Electrical Conductivity Measurement in Soils Using Time Domain Reflectometry, Vadose Zone J., 2, 444-475, 2003.

Robinson, D. A., Campbell, C. S., Hopmans, J. W., Hornbuckle, B. K., Jones, S. B., Knight, R., Ogden, F., Selker, J., and Wendroth, O.: Soil Moisture Measurement for Ecological and Hydrological Watershed-Scale Observatories: A Review, Vadose Zone J., 7, 358-389, doi:10.2136/vzj2007.0143, 2008.

Roth, K., Schulin, R., Flühler, H., and Attinger, W.: Calibration of time domain reflectometry for water content measurement using a composite dielectric approach, Water Resour. Res., 26, 22672273, doi:10.1029/WR026i010p02267, 1990.

Roth, K., Wollschläger, U., Cheng, Z. H., and Zhang, J. B.: Exploring soil layers and water tables with ground-penetrating radar, Pedosphere, 14, 273-282, 2004.

Rucker, D. F. and Ferré, T. P. A.: Parameter Estimation for Soil Hydraulic Properties Using Zero-Offset Borehole Radar, Soil Sci. Soc. Am. J., 68, 1560-1567, doi:10.2136/sssaj2004.1560, 2004.

Slater, L. and Comas, X.: Water table detection/monitoring, in: Ground Penetrating Radar: Theory and Applications, chap. 7.6.2, 1st Edn., edited by: Jol, H. M., Elsevier Science Ltd, Amsterdam, the Netherlands, 228-229, 2009.

Slob, E., Sato, M., and Olhoeft, G.: Surface and borehole groundpenetrating-radar developments, Geophysics, 75, 75A10375A120, doi:10.1190/1.3480619, 2010.
Steelman, C. M. and Endres, A. L.: An examination of direct ground wave soil moisture monitoring over an annual cycle of soil conditions, Water Resour. Res., 46, W11533, doi:10.1029/2009WR008815, 2010.

Strobbia, C. and Cassiani, G.: Multilayer ground-penetrating radar guided waves in shallow soil layers for estimating soil water content, Geophysics, 72, J17-J29, doi:10.1190/1.2716374, 2007.

Tran, A. P., Vanclooster, M., Zupanski, M., and Lambot, S.: Joint estimation of soil moisture profile and hydraulic parameters by ground-penetrating radar data assimilation with maximum likelihood ensemble filter, Water Resour. Res., 50, 3131-3146, doi:10.1002/2013WR014583, 2014.

Truss, S., Grasmueck, M., Vega, S., and Viggiano, D. A.: Imaging rainfall drainage within the Miami oolitic limestone using high-resolution time-lapse ground-penetrating radar, Water Resour. Res., 43, W03405, doi:10.1029/2005WR004395, 2007.

van der Kruk, J., Streich, R., and Green, A. G.: Properties of surface waveguides derived from separate and joint inversion of dispersive TE and TM GPR data, Geophysics, 71, K19-K29, doi:10.1190/1.2168011, 2006.

van der Kruk, J., Jacob, R. W., and Vereecken, H.: Properties of precipitation-induced multilayer surface waveguides derived from inversion of dispersive TE and TM GPR data, Geophysics, 75, WA263-WA273, doi:10.1190/1.3467444, 2010.

Van Genuchten, M.: A Closed-form Equation for Predicting the Hydraulic Conductivity of Unsaturated Soils, Soil Sci. Soc. Am. J., 44, 892-898, doi:10.2136/sssaj1980.03615995004400050002x, 1980.

Vereecken, H., Huisman, J. A., Bogena, H., Vanderborght, J., Vrugt, J. A., and Hopmans, H. J.: On the value of soil moisture measurements in vadose zone hydrology: A review, Water Resour. Res., 44, W00D06, doi:10.1029/2008WR006829, 2008.

Weihermüller, L., Huisman, J., Lambot, S., Herbst, M., and Vereecken, H.: Mapping the spatial variation of soil water content at the field scale with different ground penetrating radar techniques, J. Hydrol., 340, 205-216, doi:10.1016/j.jhydrol.2007.04.013, 2007.

Westermann, S., Wollschläger, U., and Boike, J.: Monitoring of active layer dynamics at a permafrost site on Svalbard using multichannel ground-penetrating radar, The Cryosphere, 4, 475-487, doi:10.5194/tc-4-475-2010, 2010.

Wollschläger, U., Gerhards, H., Yu, Q., and Roth, K.: Multi-channel ground-penetrating radar to explore spatial variations in thaw depth and moisture content in the active layer of a permafrost site, The Cryosphere, 4, 269-283, doi:10.5194/tc-4-269-2010, 2010 . 